\title{
GMR
}

\section{Brazilian strain of bovine respiratory coronavirus is derived from dual enteric and respiratory tropism}

E.A. Beuttemmuller ${ }^{1}$, A.F. Alfieri ${ }^{1}$, S.A. Headley ${ }^{2}$ and A.A. Alfieri ${ }^{3}$

${ }^{1}$ Laboratório Multiusuário em Saúde Animal, Unidade de Biologia Molecular, Departamento de Medicina Veterinária Preventiva, Universidade Estadual de Londrina, Londrina, PR, Brasil

${ }^{2}$ Laboratório de Patologia Animal,

Departamento de Medicina Veterinária Preventiva, Universidade Estadual de Londrina, Londrina, PR, Brasil

${ }^{3}$ Laboratório de Virologia Animal, Departamento de Medicina Veterinária Preventiva, Universidade Estadual de Londrina, Campus Universitário, Londrina, PR, Brasil

Corresponding author: A.A. Alfieri

E-mail: alfieri@uel.br

Genet. Mol. Res. 16 (2): gmr16029580

Received December 12, 2016

Accepted February 24, 2017

Published April 5, 2017

DOI http://dx.doi.org/10.4238/gmr16029580

Copyright (C) 2017 The Authors. This is an open-access article distributed under the terms of the Creative Commons Attribution ShareAlike (CC BY-SA) 4.0 License.

\begin{abstract}
Bovine coronavirus (BCoV) is a pathogen related to enteric and respiratory diseases in cattle worldwide. Enteric (BECoV) strains of $\mathrm{BCoV}$ are predominant in South America, and genetic investigations have been conducted to identify its relationship with isolates of respiratory origin (BRCoV). In this study, we used a BRCoV strain (BR-UEL11) derived from an outbreak of respiratory disease in feedlot cattle in southern Brazil, and compared the partial sequence of the polymorphic region of Spike (which was detected and sequenced by two distinct reverse transcription-polymerase chain reactions) with those of other $\mathrm{BCoV}$ strains. The phylogenetic relationship of BRUEL11 with Brazilian $\mathrm{BCoV}$, which is associated with calf diarrhea
\end{abstract}

Genetics and Molecular Research 16 (2): gmr16029580 
and winter dysentery (enteric, BECoV; respiratory, BRCoV), and classical reference prototypes was analyzed. The analysis showed that the BRCoV strains from Brazil clustered with a clade that was distinct from most isolates associated with calf diarrhea (BECoV) and ancestral prototype strains such as Mebus, Nebraska, and LYVB. Furthermore, the BRCoV strains from Brazil clustered with a clade that contained recent strains associated with winter dysentery, showing 98-99\% nucleotide identity with those strains. These results suggested that the Brazilian $\mathrm{BCoV}$ evolved from being solely enteric to a dual enteric and respiratory tropic virus.

Key words: Bovine coronavirus; Bovine respiratory disease; Spike glycoprotein; Dual tropism; Phylogeny

\section{INTRODUCTION}

Coronaviruses cause respiratory and enteric disease in humans, birds, and other mammals (Siddell et al., 1983, Woo et al., 2009). The bovine coronavirus (BCoV) is a global pathogen that is recognized as the causative agent of enteric disease; however, the contribution of this pathogen towards the development of bovine respiratory disease (BRD) was underestimated compared to those of viruses that are primary agents of $\mathrm{BRD}$, such as the bovine herpesvirus 1, bovine viral diarrhea virus, bovine parainfluenza-3 virus, and bovine respiratory syncytial virus (Fulton et al., 2011). However, recent reports have indicated that BCoV might also be a major pathogen of BRD (Lathrop et al., 2000; Boileau and Kapil, 2010; Hick et al., 2012). Moreover, isolates of $\mathrm{BCoV}$ associated with neonatal and adult diarrhea are referred to as BECoV (bovine enteric or enteropathogenic coronaviruses), whereas strains isolated from nasal secretions and lung of cattle affected by pneumonia have been classified as bovine respiratory coronaviruses, BRCoV (Lin et al., 2000; Boileau and Kapil, 2010).

$\mathrm{BCoV}$ is a ubiquitous betacoronavirus within the subfamily Coronavirinae, family Coronaviridae (ICTV: http://www.ictvonline.org/virustaxonomy.asp). The virus is enveloped and pleomorphic, with a single-stranded positive-sense RNA genome. It has two major outer glycoproteins, namely, Spike (S), which is further divided into domains S1 and S2 (Cavanagh, 1983), and hemagglutinin-esterase (HE) (Hasoksuz et al., 2002). S1 is the receptor-binding domain responsible for viral attachment and entry into the host cell, whereas S2 is related to membrane fusion. Therefore, $\mathrm{S}$ glycoproteins and $\mathrm{HE}$ are major neutralizing antigens of BCoV (Saif, 1993; Lin et al., 2000). Mutations in the S protein, mostly in the S1 domain, are associated with variations in the host range, tissue tropism, pathogenicity, and antigenic differences among strains (Saif, 2010).

Worldwide, $\mathrm{BCoV}$ is associated with $\mathrm{BRD}$ in cattle of all ages, shipping fever, calf diarrhea, winter dysentery (Boileau and Kapil, 2010), and dysentery during the warmer seasons (Park et al., 2006; Decaro et al., 2008). Consequently, BCoV can simultaneously cause enteric and respiratory infections in the same animal (Park et al., 2007), although genetic markers for distinguishing between strains with both types of tropism were not identified during molecular analysis of the S glycoprotein (Kanno et al., 2007). Phylogenetic analyses based on the S-encoding gene sequence was performed in South Korea (Park et al., 2006), Japan (Kanno et al., 2007), and the USA (Fulton et al., 2013), which revealed that ancestral

Genetics and Molecular Research 16 (2): gmr16029580 
reference strains of $\mathrm{BCoV}$ that are exclusively associated with enteric manifestations clustered within a distinct phylogenetic group compared to the recent isolates associated with enteric and respiratory diseases.

Since the first description of a Brazilian $\mathrm{BCoV}$ associated with calf diarrhea, most Brazilian strains of enteric origin have now been described and characterized by molecular methods (Jerez et al., 2005; Takiuchi et al., 2008; Stipp et al., 2009; Ribeiro et al., 2016); in addition, assessment of major public databases did not reveal any description of BRCoV in other South American countries. This study investigates the recent molecular evolution of $\mathrm{BCoV}$ by addressing the phylogenetic relationship between the enteric and winter dysentery strains based on a polymorphic region of the Brazilian $\mathrm{BRCoV}$.

\section{MATERIAL AND METHODS}

The BRCoV strain (BR-UEL11) was derived from nasopharyngeal swabs collected during an outbreak of BRD in feedlot cattle from the State of Paraná, southern Brazil. Nucleic acid purification was performed as described (Boom et al., 1990), and the presence of BCoV was confirmed using a semi-nested polymerase chain reaction (PCR) targeting the $N$ gene (Takiuchi et al., 2006). For genetic analysis, a reverse transcription (RT)-PCR assay using the SPK5 pair of primers (Takiuchi et al., 2008) was used to amplify the sequence encoding the nucleotides 1256 to 1904 based on the $S$ gene of the Mebus strain (accession number U00735.2), which includes the polymorphic region (nucleotides 1368 - 1776) (Rekik and Dea, 1994). All amplicons were visualized on an ethidium bromide-stained $2 \%$ agarose gel. The PCR products were purified using the GFXTM PCR DNA and gel band purification kit (GE Healthcare, Little Chalfont, UK) and sequenced (ABI3500 Genetic Analyzer, Applied Biosystems) using the forward and reverse primers with the BigDye ${ }^{\mathrm{TM}}$ Terminator v3.1 cycle sequencing kit (Applied Biosystems, Foster City, CA, USA).

The phylogenetic analyses compared the BRCoV strain, BR-UEL11 (GenBank accession No. KP208779), with 67 Brazilian strains of BECoV and BRCoV, which were available in the GenBank. Furthermore, reference strains of respiratory origin, such as OK0514-3 (AF058944) (Chouljenko et al., 1998), 232NS (DQ320763.1), the winter dysentery strain KW10, and the classical calf diarrhea prototype enteric strains Mebus (U00735) (Stair et al., 1972), Nebraska (JQ741969), and the Brazilian LYVB strain (AY606205) (Brandão et al., 2006) were included in the study. To include all available data (from the Genbank) pertaining to the Brazilian $\mathrm{BCoV}$, phylogenetic analysis was performed by evaluating the partial sequence of the polymorphic region (nucleotides 1388-1712). The phylogenetic relationship was constructed using the MEGA 7.0 software. The nucleotide sequences were aligned with Clustal W, and the phylogenetic analysis was performed using maximum likelihood's Tamura 3-parameter model and 1,000 bootstrap replications.

\section{RESULTS}

The phylogenetic analysis of nucleotide sequences from the polymorphic region revealed two groups that form the major clades 1 and 2 (Figure 1). Clade 1 consists of the BECoV strains from Brazil (USP- 2 to 14) derived from stool samples of calves affected with the winter dysentery WDBR-01 strain, and the ancestral calf diarrhea reference strains LYVB, Mebus, and Nebraska. A deletion of 18 nucleotides from positions 1577 to 1594 of the $S$

Genetics and Molecular Research 16 (2): gmr16029580 
gene, which is exactly at the polymorphic region (Brandão et al., 2006), was present in all the Brazilian strains and the reference LYVB strain within clade 1.

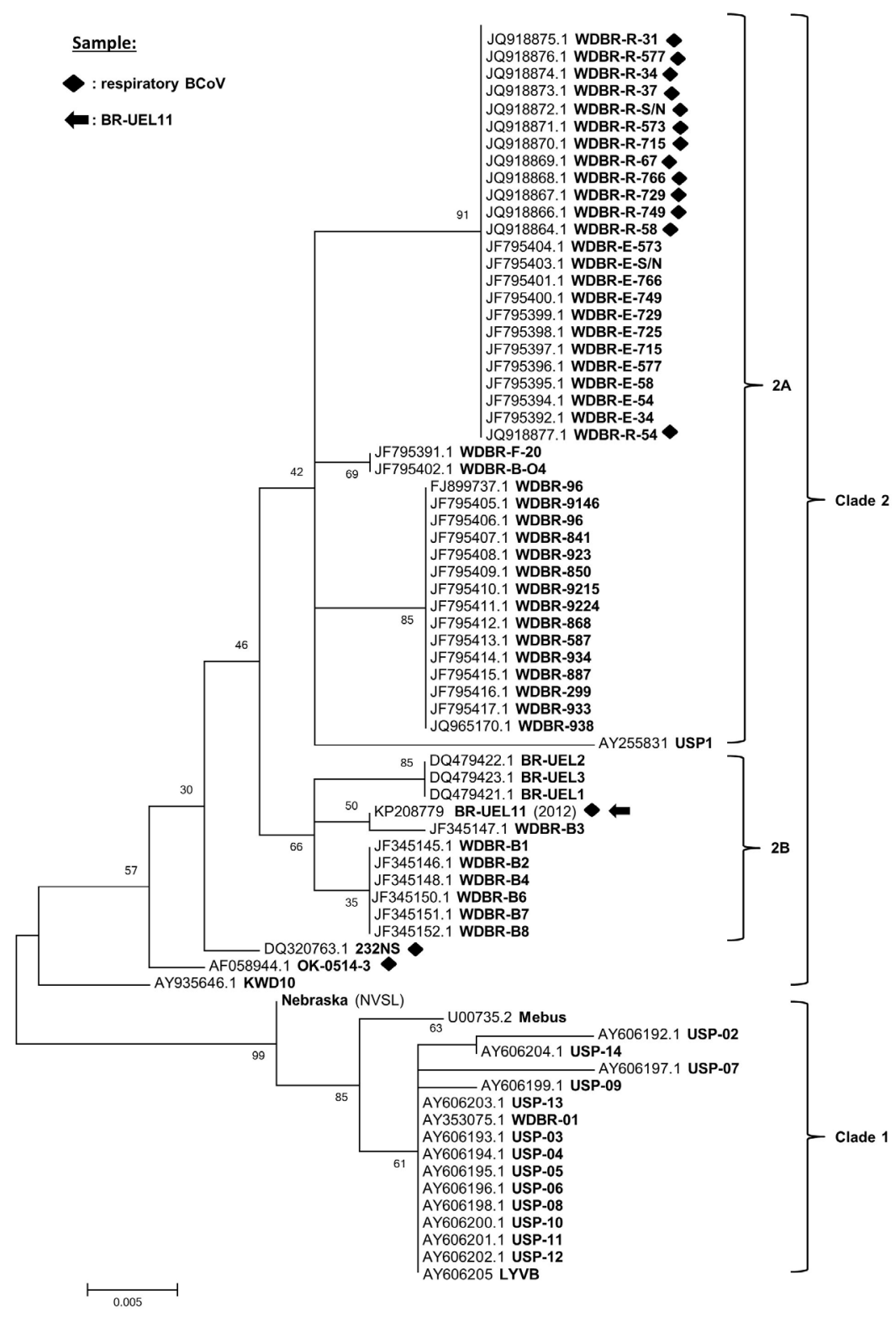

Figure 1. Phylogenetic relationship, based on the partial sequence of the polymorphic region (nucleotides 13881712), of selected Brazilian strains of bovine coronavirus with prototype strains of BECoV and BRCoV. The nucleotide sequences were identified by GenBank accession number and strain name. BRCoV strains are denoted by a black diamond and BR-UEL11 with an arrow. The tree was generated using the maximum likelihood method with bootstrap values of 1000 replicates.

Genetics and Molecular Research 16 (2): gmr16029580 
Most of the Brazilian BRCoV strains clustered in clade 2, including the respiratory strain BR-UEL11 identified during the outbreak of BRD (Figure 1), and other respiratory strains from Brazil. This clade also contained the respiratory prototypes OK-0514-3 and 232NS, as well as the winter dysentery KWD10 strain. Additionally, two subclades, 2A and 2B, were formed by viruses that originated from Brazil. Subclade 2B consisted of the respiratory BRUEL11 strain, winter dysentery strains of enteric origin, and the BR-UEL 1, 2, and 3 strains obtained from diarrheic calves (Takiuchi et al., 2008). The subclade 2A consisted of several winter dysentery strains of enteric and respiratory origin and USP-1 from calf stool; however, no nucleotide deletion gaps, as observed in the USP strains of clade 1, were identified.

Calculation of the genetic distance among strains revealed that the BR-UEL11 strain shared 99 to $98 \%$ nucleotide identity with similar strains from Brazil within clade 2, but only 91 to $90 \%$ identity with strains from Brazil in clade 1, which harbored the 18 nucleotide gap in their sequence. Compared to the prototype strains, BR-UEL11 showed a nucleotide identity of $91 \%$ with LYVB, 96\% with Mebus, 97\% with Nebraska, 98\% with KW10, and 99\% with the OK-0514-3 and 232NS respiratory strains.

\section{DISCUSSION}

This study demonstrated the phylogenetic relationship among BCoV strains identified and analyzed in Brazil predominantly from 2003 to 2010. In addition, a sequence of the S1 polymorphic region of a BRCoV strain identified in Brazil in 2012 was included in the study. Previous studies have suggested that genetic changes in the gene encoding the $\mathrm{S}$ protein of field strains may interfere with the humoral protection elicited by vaccination because vaccines are generally manufactured using the old prototype strains as antigens (Hussain et al., 1991; Lee et al., 2010; Kanno et al., 2013). Currently, commercial vaccines against respiratory pathogens of cattle containing BCoV-derived antigens are lacking in Brazil. Vaccines containing BCoV were developed to prevent calf diarrhea, being formulated only in association with other enteric pathogens. However, empirical analysis based on molecular diagnosis (data not shown) suggests that respiratory strains of $\mathrm{BCoV}$ may be significantly prevalent in Brazilian feedlots.

Older hypotheses posit that $\mathrm{BCoV}$ strains have genetically evolved from the ancestral enteric viruses to distinct respiratory and enteric strains, which are distant from the old prototypes responsible for calf diarrhea and winter dysentery (Hasoksuz et al., 2002). However, based on the analysis of the $S$ gene of South Korean isolates, where strains associated with dysentery clustered with a $\mathrm{BRCoV}$ isolate and were distant from the classic Mebus prototype, it was hypothesized that the same strain could cause both respiratory and enteric disease, and that $\mathrm{BCoV}$ had evolved to possess dual tropism (enteric and respiratory) (Park et al., 2006). To investigate this possibility, an experiment was performed with the South Korean winter dysentery strain KWD3, which showed that calves developed diarrhea without clinical manifestation of respiratory disease, whereas histopathology demonstrated mild to severe interstitial pneumonia caused by the KWD3 strain (Park et al., 2007).

Phylogenetic analysis of the Brazilian strains revealed that the respiratory BRUEL11 and WDBR-R-(x) strains clustered within a distinct clade that was distant from the old enteric $\mathrm{BCoV}$ prototypes. Clade 1 contained the old prototypes such as LYVB, Mebus, and Nebraska, whereas clade 2 contained more recent strains associated with winter dysentery and respiratory tract disease (Figure 1). Similar results were obtained upon analyzing the $S$ gene of winter dysentery strains in Japan (Kanno et al., 2007), and with isolates of enteric and

Genetics and Molecular Research 16 (2): gmr16029580 
respiratory origin from the USA (Fulton et al., 2013). These findings support the theory that this phylogenetic distribution resulted from the evolution of $\mathrm{BCoV}$ strains to possess dual enteric and respiratory tropism.

In a phylogenetic analysis with strains from the USA (Fulton et al., 2013), one clade that contained more recent respiratory and winter dysentery strains further diverged into subclades, which varied antigenically. These differences were assessed by virus neutralization, using convalescent cattle sera raised against all the American subclades that cross-react with each other, and the Nebraska prototype strain from a distinct clade (Fulton et al., 2013). Thus, the observed antigenic differences suggest that vaccines manufactured with calf diarrhea prototypes, such as the Mebus strain, may have reduced efficiency against certain strains circulating in the USA. The same phenomenon might occur with certain strains of other countries such as Brazil. However, challenge studies in validated animal models are required to ascertain the correlation between strain-specific antigenic distances and efficiency of vaccine protection in cattle infected with the current Brazilian field strains of BCoV (Fulton et al., 2015).

In conclusion, we have demonstrated that the respiratory and enteric winter dysentery strains of the Brazilian bovine coronavirus included in this analysis are distant from the ancestral LYVB, Mebus, Nebraska, and old field strains that clustered with prototypes related to calf diarrhea. These findings suggest that the $\mathrm{BCoV}$ strains of Brazil probably diverged from enteric to dual tropism, and currently the same strain is associated with both enteric and respiratory diseases. In addition, since the Spike protein is the major neutralizing antigen of coronaviruses, the differences in the $S$ gene sequence between the Brazilian strains and the old $\mathrm{BCoV}$ prototypes highlight the importance of assessing the efficacy of vaccines raised against the current field strains in Brazil.

\section{ACKNOWLEDGMENTS}

The authors thank the following Brazilian Institutes for financial support: Conselho Nacional de Desenvolvimento Científico e Tecnológico (CNPq), Coordenação de Aperfeiçoamento de Pessoal de Nível Superior (CAPES), Financing of Studies and Projects (FINEP), and the Araucaria Foundation (FAP/PR). A.F. Alfieri, S.A. Headley, and A.A. Alfieri are recipients of CNPq fellowships and grants.

\section{REFERENCES}

Boileau MJ and Kapil S (2010). Bovine coronavirus associated syndromes. Vet. Clin. North Am. Food Anim. Pract. 26: 123-146. http://dx.doi.org/10.1016/j.cvfa.2009.10.003

Boom R, Sol CJ, Salimans MM, Jansen CL, et al. (1990). Rapid and simple method for purification of nucleic acids. $J$. Clin. Microbiol. 28: 495-503.

Brandão PE, Gregori F, Richtzenhain LJ, Rosales CA, et al. (2006). Molecular analysis of Brazilian strains of bovine coronavirus $(\mathrm{BCoV})$ reveals a deletion within the hypervariable region of the $\mathrm{S} 1$ subunit of the spike glycoprotein also found in human coronavirus OC43. Arch. Virol. 151: 1735-1748. http://dx.doi.org/10.1007/s00705-006-0752-9

Cavanagh D (1983). Coronavirus IBV: structural characterization of the spike protein. J. Gen. Virol. 64: 2577-2583. http:// dx.doi.org/10.1099/0022-1317-64-12-2577

Chouljenko VN, Kousoulas KG, Lin X and Storz J (1998). Nucleotide and predicted amino acid sequences of all genes encoded by the $3^{\prime}$ genomic portion $(9.5 \mathrm{~kb})$ of respiratory bovine coronaviruses and comparisons among respiratory and enteric coronaviruses. Virus Genes 17: 33-42. http://dx.doi.org/10.1023/A:1008048916808

Decaro N, Mari V, Desario C, Campolo M, et al. (2008). Severe outbreak of bovine coronavirus infection in dairy cattle

Genetics and Molecular Research 16 (2): gmr16029580 
during the warmer season. Vet. Microbiol. 126: 30-39. http://dx.doi.org/10.1016/j.vetmic.2007.06.024

Fulton RW, Step DL, Wahrmund J, Burge LJ, et al. (2011). Bovine coronavirus (BCV) infections in transported commingled beef cattle and sole-source ranch calves. Can. J. Vet. Res. 75: 191-199.

Fulton RW, Ridpath JF and Burge LJ (2013). Bovine coronaviruses from the respiratory tract: antigenic and genetic diversity. Vaccine 31: 886-892. http://dx.doi.org/10.1016/j.vaccine.2012.12.006

Fulton RW, Herd HR, Sorensen NJ, Confer AW, et al. (2015). Enteric disease in postweaned beef calves associated with Bovine coronavirus clade 2. J. Vet. Diagn. Invest. 27: 97-101. http://dx.doi.org/10.1177/10406387145559026

Hasoksuz M, Sreevatsan S, Cho KO, Hoet AE, et al. (2002). Molecular analysis of the S1 subunit of the spike glycoprotein of respiratory and enteric bovine coronavirus isolates. Virus Res. 84: 101-109. http://dx.doi.org/10.1016/S0168-1702(02)00004-7

Hick PM, Read AJ, Lugton I, Busfield F, et al. (2012). Coronavirus infection in intensively managed cattle with respiratory disease. Aust. Vet. J. 90: 381-386. http://dx.doi.org/10.1111/j.1751-0813.2012.00978.x

Hussain KA, Storz J and Kousoulas KG (1991). Comparison of bovine coronavirus (BCV) antigens: monoclonal antibodies to the spike glycoprotein distinguish between vaccine and wild-type strains. Virology 183: 442-445. http:// dx.doi.org/10.1016/0042-6822(91)90163-6

Jerez JA, Gregori F, Brandão PE, Rodriguez CAR, et al. (2005). Isolation of bovine coronavirus (BCoV) in monolayers of HmLu-1 cells. Braz. J. Microbiol. 36: 207-210. http://dx.doi.org/10.1590/S1517-83822005000300001

Kanno T, Hatama S, Ishihara R and Uchida I (2007). Molecular analysis of the S glycoprotein gene of bovine coronaviruses isolated in Japan from 1999 to 2006. J. Gen. Virol. 88: 1218-1224. http://dx.doi.org/10.1099/vir.0.82635-0

Kanno T, Ishihara R, Hatama S and Uchida I (2013). Antigenic variation among recent Japanese isolates of bovine coronaviruses belonging to phylogenetically distinct genetic groups. Arch. Virol. 158: 1047-1053. http://dx.doi. org/10.1007/s00705-012-1587-1

Lathrop SL, Wittum TE, Brock KV, Loerch SC, et al. (2000). Association between infection of the respiratory tract attributable to bovine coronavirus and health and growth performance of cattle in feedlots. Am. J. Vet. Res. 61: 10621066. http://dx.doi.org/10.2460/ajvr.2000.61.1062

Lee G, Song J, Cho I and Yoon S (2010). Cross-reactivity of vaccine and field strains of bovine coroviruses in Korea. $J$. Bacterian. Virol. 40: 49-58. http://dx.doi.org/10.4167/jbv.2010.40.1.49

Lin XQ, O eilly KL, Storz J, Purdy CW, et al. (2000). Antibody responses to respiratory coronavirus infections of cattle during shipping fever pathogenesis. Arch. Virol. 145: 2335-2349. http://dx.doi.org/10.1007/s007050070024

Park SJ, Jeong C, Yoon SS, Choy HE, et al. (2006). Detection and characterization of bovine coronaviruses in fecal specimens of adult cattle with diarrhea during the warmer seasons. J. Clin. Microbiol. 44: 3178-3188. http://dx.doi. org/10.1128/JCM.02667-05

Park SJ, Kim GY, Choy HE, Hong YJ, et al. (2007). Dual enteric and respiratory tropisms of winter dysentery bovine coronavirus in calves. Arch. Virol. 152: 1885-1900. http://dx.doi.org/10.1007/s00705-007-1005-2

Rekik MR and Dea S (1994). Comparative sequence analysis of a polymorphic region of the spike glycoprotein S1 subunit of enteric bovine coronavirus isolates. Arch. Virol. 135: 319-331. http://dx.doi.org/10.1007/BF01310017

Ribeiro J, Lorenzetti E, Alfieri AF and Alfieri AA (2016). Molecular detection of bovine coronavirus in a diarrhea outbreak in pasturefeeding Nellore steers in southern Brazil. Trop. Anim. Health Prod. 48: 649-653. http://dx.doi.org/10.1007/s11250-015-0975-4

Saif LJ (1993). Coronavirus immunogens. Vet. Microbiol. 37: 285-297. http://dx.doi.org/10.1016/0378-1135(93)90030-B

Saif LJ (2010). Bovine respiratory coronavirus. Vet. Clin. North Am. Food Anim. Pract. 26: 349-364. http://dx.doi. org/10.1016/j.cvfa.2010.04.005

Siddell S, Wege H and Ter Meulen V (1983). The biology of coronaviruses. J. Gen. Virol. 64: 761-776. http://dx.doi. org/10.1099/0022-1317-64-4-761

Stair EL, Rhodes MB, White RG and Mebus CA (1972). Neonatal calf diarrhea: purification and electron microscopy of a coronavirus-like agent. Am. J. Vet. Res. 33: 1147-1156.

Stipp DT, Barry AF, Alfieri AF, Takiuchi E, et al. (2009). Frequency of BCoV detection by a semi-nested PCR assay in faeces of calves from Brazilian cattle herds. Trop. Anim. Health Prod. 41: 1563-1567. http://dx.doi.org/10.1007/ $\underline{\text { s11250-009-9347-2 }}$

Takiuchi E, Stipp DT, Alfieri AF and Alfieri AA (2006). Improved detection of bovine coronavirus N gene in faeces of calves infected naturally by a semi-nested PCR assay and an internal control. J. Virol. Methods 131: 148-154. http:// dx.doi.org/10.1016/j.jviromet.2005.08.005

Takiuchi E, Alfieri AF and Alfieri AA (2008). Molecular analysis of the bovine coronavirus S1 gene by direct sequencing of diarrheic fecal specimens. Braz. J. Med. Biol. Res. 41: 277-282. http://dx.doi.org/10.1590/S0100879X2008000400004

Woo PCY, Lau SKP, Huang Y and Yuen K-Y (2009). Coronavirus diversity, phylogeny and interspecies jumping. Exp. Biol. Med. (Maywood) 234: 1117-1127. http://dx.doi.org/10.3181/0903-MR-94

Genetics and Molecular Research 16 (2): gmr16029580 